\title{
Perspectives of Hospital Pharmacists Towards Biosimilar Medicines: A Survey of Polish Pharmacy Practice in General Hospitals
}

\author{
Iga Pawłowska ${ }^{1}$ (D) $\cdot$ Leszek Pawłowski $^{2}$ (D) $\cdot$ Natalia Krzyżaniak $^{3}$ (D) Ivan Kocić $^{1}$ (D)
}

Published online: 4 March 2019

(c) The Author(s) 2019

\begin{abstract}
Introduction There has been a significant increase in the volume of biosimilar medicines recently due to the expiries of patent protections of biologic medicines. Biosimilars are considered new medicines, and their usage in therapy is often associated with uncertainty from the perspectives of physicians, pharmacists and patients.

Objectives The purpose of this study was to identify hospital pharmacist opinions towards these new medicines and investigate their usage in practice.

Methods A paper-based, self-administered questionnaire was distributed to Polish hospital pharmacists.

Results Biosimilars were used in $77 \%$ of surveyed hospitals, whereas originator biologics were utilised within $90 \%$ of settings. The former medicines were found to consist of less than one-third of the entire course of biological pharmacotherapy used within Polish hospitals. A total of $88 \%$ of hospital pharmacists were concerned that the new drugs were not identical with the biologic versions, $48 \%$ with their immunogenicity and $44 \%$ with other pharmacokinetic properties. The majority of respondents (87\%) stated that the most important advantage of biosimilars related to decreased costs. Furthermore, according to participants, pharmacist-led substitution is not appropriate.

Conclusion Due to the numerous concerns relating to the usage of biosimilars, their introduction into patient therapy requires special attention from healthcare providers. While pharmacists involved in the distribution of biosimilars are conscious of their impact in decreasing costs of therapy, they do not feel comfortable in recommending their substitution without a physician's permission. There is a need for more precise legal regulations relating to biosimilars, improved communication between physicians and pharmacists, as well as educational initiatives to improve the safe and effective usage of biosimilars.
\end{abstract}

\section{Key Points}

Biosimilars were found to be used within Polish hospitals; however, originator biologics are still more commonly utilised in practice.

Hospital pharmacists are aware of these new drugs and they perceive these biosimilars positively in terms of their cost effectiveness.

Pharmacists expressed concerns about perceived differences between biologics and biosimilars as well as their immunogenicity and pharmacist-led substitution of biosimilars.

Iga Pawłowska

iga112@gumed.edu.pl

1 Department of Pharmacology, Medical University of Gdańsk, Dębowa Str. 23, 80-204 Gdańsk, Poland

2 Department of Palliative Medicine, Medical University of Gdańsk, Gdańsk, Dębinki Str. 2, 80-211 Gdańsk, Poland

\section{Introduction}

Many biological medicines (reference medicines) have a competitive version, produced by other manufacturers from other cell lines, known as biosimilar medicines (biosimilars). They are not identical, but have functional and structural similarities, which should be reflected in their safety, efficacy and clinical properties [1-3]. Biosimilars are new medicines that were first approved by the European Medicines Agency (EMA) in 2006 [4]. The first biosimilar used in Europe contained somatropin [recombinant human growth hormone (rhGH)] [5]. These new medicines have now become a big part of biological therapies used by

3 Department of Pharmacy, Graduate School of Health, University of Technology Sydney, 638 Jones Street, Broadway, Ultimo, NSW, Australia 
many specialists in the treatment of rheumatoid arthritis, cancer, Crohn's diseases, colitis, diabetes mellitus, osteoporosis, anaemia, immunologic diseases and other ailments, both in adults and in children [6-8]. At the time of writing (2018), 15 originator biological drugs had corresponding centrally authorised biosimilar medicines, which have been approved for therapy by the EMA (47 products), including adalimumab, bevacizumab, enoxaparin sodium, epoetin alfa, epoetin zeta, etanercept, filgrastim, follitropin alfa, infliximab, insulin glargine, insulin lispro, pegfilgrastim, rituximab, somatropin, teriparatide and trastuzumab $[9,10]$. The EMA states that biosimilarity means a high similarity profile in terms of structure, biological activity, efficacy, safety and immunogenicity to the original product [11]. However, biosimilars are complex proteins and therefore these medicines will never be an identical duplicate of the original, due to their heterogeneous nature, high molecular weight, batch-to-batch variability and complexity [12]. Moreover, the process of manufacturing them requires living cells and may vary based on specific production conditions. In contrast to the originator biologics approval process, which requires a comprehensive clinical evaluation of efficacy and safety, comparative studies are conducted for the approval of biosimilars; however, efficacy is not tested as such. After approval, both originator biologics and biosimilars must undergo the same level of safety monitoring [13].

The literature has highlighted reservations from the perspectives of healthcare professionals about switching from an original medicine to a biosimilar or vice versa during patient therapy. In Europe, the EMA does not regulate interchangeability, switching or substitution; these must be regulated by each country according to their law or national regulatory authorities $[2,13,14]$. The Polish regulatory body does not specifically authorise the exchange of originator biologics and biosimilars. The national 'Pharmaceutical Law' allows the interchange of original medicine and generics unless there is direction written on the prescription by the physician of 'do not change' [15]. However, due to their nature, all biologic medicines cannot be considered as other chemical medicines and the aforementioned legislative entry must not encompass originator biologics and biosimilars.

Currently, not only physicians, but also other healthcare professionals, are involved in biosimilar distribution, application and usage. Stevenson et al. [16] believe that pharmacists will play a key role in managing the introduction of biosimilars into healthcare systems. In Poland, hospital pharmacists are specifically responsible for the dispensing of drugs, including biosimilars, their safe storage and documentation. Moreover, they are members of hospital therapeutic teams, which are responsible for drug management and medication policies within hospitals [17].
In light of the growing availability of biosimilars and the current level of hospital pharmacy services in Poland, this study aimed to identify pharmacy practices related to the usage of biosimilars within hospitals. A specific objective aimed to assess hospital pharmacists' knowledge of and attitudes towards this new group of medicines.

\section{Methods}

This was a questionnaire-based study. The participants of the survey were hospital pharmacists (including directors of hospital pharmacies) employed at every general (teaching and non-teaching) hospital in Poland. The total number of hospitals was 271, and these sites were selected from the publicly accessible web database of Health Care Institutions.

The questionnaire was sent by post to all recruited hospital pharmacies with an invitation letter explaining the purpose of the study. The respondents were asked to complete the questionnaire form and return it within 2 weeks by post, fax or email. Participants were also able to complete an electronic version of the survey following an email request. The survey was non-interventional, anonymous, self-administered and voluntary. The participants did not receive any incentives for participating in this study.

The questionnaire was written in Polish and consisted of 12 short questions, which were developed based on the available literature and the researchers' own experience. Some of the questions involved binary choice answers, and the rest included multiple-choice answers. The first section of the survey included four questions relating to the background characteristics of the respondents. The second part consisted of eight questions dedicated to the main subject of the study. The first question from this section related to knowledge of biosimilars. The next three questions were related to the usage of originator biologic and biosimilar medicines in practice at the examined hospitals. In the last four items, the participants were asked to express their opinion about biosimilars. Moreover, each respondent could write his own suggestions concerning the examined medicines. The survey was conducted in September 2017.

\subsection{Statistical Analysis}

The responses for each question were collected and calculated (frequencies and percentages) using Microsoft Excel $^{\circledR}$ (Microsoft Corp., Redmond, WA, USA) and Statistica ${ }^{\mathrm{TM}}$ (TIBCO Software Inc., Palo Alto, CA, USA). For the statistical analysis, the Chi-square test was applied to determine any correlation between the two selected variables, e.g. comparing work experience or gender of the pharmacists to 
interchanging medicines, and pharmacist specialisation to the usage to biosimilars (Statistica version 12).

\section{Results}

Overall, 61 of 271 questionnaires were completed by pharmacists and included in the analysis (response rate 22.51\%). Most surveys were fully completed $(100 \%$ of questions answered). However, there were a few questionnaires with incomplete single questions. Therefore, in some cases, the total number of answers to individual questions was less than 61 .

The background characteristics highlighted that most of the respondents were middle-aged females, with more than 10 years' experience working within hospital pharmacies. Regarding post-graduate training, more than three-quarters of all pharmacists held a pharmacy specialisation. In Poland, pharmacists are able to specialise in various fields of practice-our study indicated that $76.1 \%$ of all examined pharmacists had at least one specialisation (and in some cases more than one). Thirty-one pharmacists (68.9\%) held a community pharmacy specialisation, 13 held a hospital pharmacy specialisation, and a clinical pharmacy specialisation was only held by five pharmacists (Table 1).

\subsection{Experience and Attitudes Towards Biosimilars}

A total of $65.6 \%(n=40)$ of hospital pharmacists were very well acquainted with biosimilars, whereas $32.8 \%$ $(n=20)$ stated that they were somewhat familiar with these new drugs, although they were aware of them, indicating that they have basic understanding of these medicines. One person answered 'not familiar' and no one declared that had never heard about these medicines. When considering established practices relating to the usage of these new drugs, the study indicated that originator biologic medicines were used at $90 \%$ of hospitals $(n=54)$, and biosimilars at $77 \%(n=47)$. There were some hospitals in which only one type of medicine was used. The respondents were also asked to compare the volumes of both biologic and biosimilar medicines used within their respective hospitals. The average ratio identified by the surveyed pharmacists was $72 \%$ originator biologics to $28 \%$ biosimilars.

The next part of the study related to the attitudes of pharmacists towards the usage of biosimilars. The majority of respondents believed that these medicines should be used at the initiation of therapy $(n=41,68 \%)$, when the original drug is ineffective $(n=23,38 \%)$ or to substitute original medicines ( $n=14,23 \%)$ (Fig. 1). Moreover, holding a specialisation does not influence pharmacists'
Table 1 Background characteristics of the hospital pharmacists $(n=60)$

\begin{tabular}{lcc}
\hline Characteristics & $n$ & $\%$ \\
\hline Age (years) & 4 & \\
$>25$ to $\leq 30$ & 14 & 6.7 \\
$>30$ to $\leq 40$ & 20 & 23.3 \\
$>40$ to $\leq 50$ & 15 & 33.3 \\
$>50$ to $\leq 60$ & 7 & 25 \\
$>60$ & & 11.9 \\
Gender & 41 & \\
Female & 19 & 68.3 \\
Male & & 31.7 \\
Post-graduate training & 46 & \\
Specialisation & \\
$\quad$ Clinical pharmacy & 5 & 76.7 \\
Hospital pharmacy & 13 & 11.1 \\
Community pharmacy & 31 & 28.9 \\
No specialisation & 14 & 68.9 \\
Length of service to the hospital pharmacy (years) & 23.3 \\
$<1$ & 3 & \\
$\geq 1$ to $\leq 3$ & 3 & 5 \\
$>3$ to $\leq 10$ & 15 & 65 \\
$>10$ & 39 &
\end{tabular}

${ }^{\mathrm{a}} 8.9 \%$ of pharmacists have more than one specialisation

attitudes towards the usage of biosimilars $(p>0.05)$, except in one case: pharmacists without specialisation more often than specialised pharmacists believed that biosimilars should be used when the reference medicines are ineffective $(p=0.04058)$. It is worth adding that 11 pharmacists indicated 'other cases' as circumstances appropriate for the usage of biosimilars: three of them enumerated a lack of the original drug on the pharmaceutical market and a lack of other therapeutic possibilities, better price, as well as examination results of the drugs demonstrating similar pharmacokinetics parameters. Also, some suggested that the therapy should be continued with the same medicine.

\subsection{Perceived Advantages and Disadvantages of Biosimilars}

The most important benefits of biosimilars were identified as being a lower price, impact on pharmacoeconomic issues and having a similar efficacy to reference medicines. The precise data are presented in Fig. 2. Participants' qualitative responses reinforced these findings and read as follows:

Participant No. 9: "The cost of the drug [biosimilar] is ok/afordable/ and the patient will buy it" 
Fig. 1 Pharmacist perspectives on circumstances in which biosimilars should be used $(n=60)$

\section{When should biosimilars be used?}

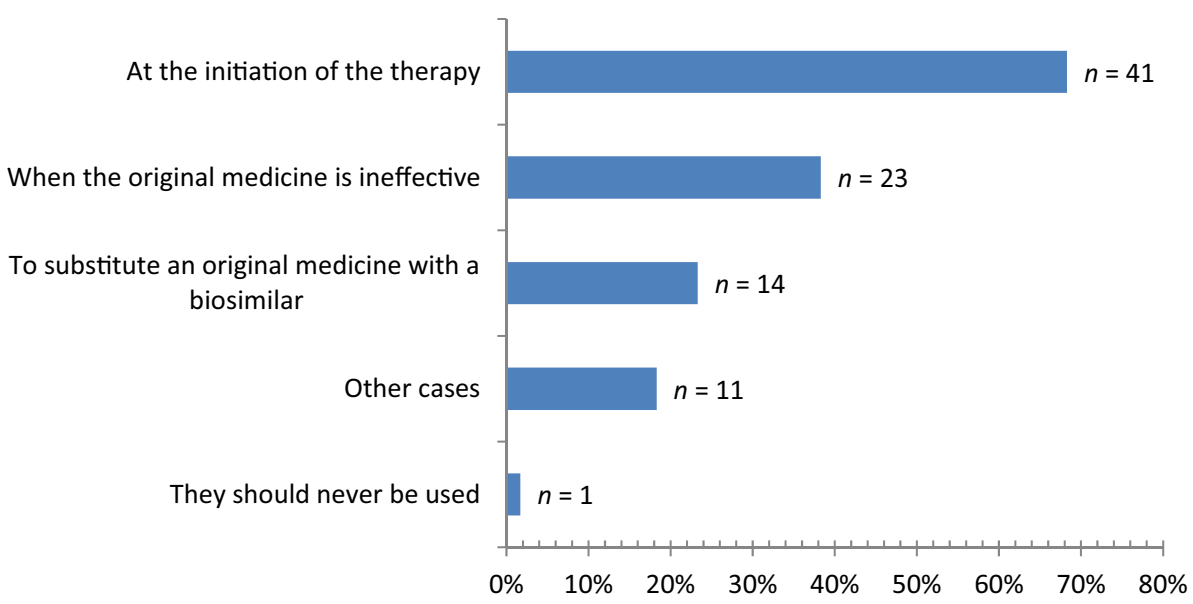

Participant No. 14: "Biosimilar does not mean that the drug is worse than an originator biologic"

Alternatively, the fact that biosimilars are not identical duplicates of originator biologics was expressed by the majority of participants (53 of 60) as the main disadvantage. Other negative characteristic features include immunogenicity, other pharmacokinetic properties and adverse drug reactions. Only seven respondents indicated lower efficacy than reference medicines (Fig. 3). One person explained:

Participant No. 14: "The biosimilar drugs differ from [originator] biologics in each level on the production."

... "Always must remember, that biosimilars are not identical as [biologics]."

At the end of the questionnaire pharmacists were asked about the interchangeability of biosimilars. Overall, three-quarters of all respondents (45 of 60) felt that pharmacists were not able to change an originator biologic to a biosimilar without the doctor's permission. Nine of 60 respondents thought that substitution was possible when the original medicine was not available. Only six participants felt that they were allowed to automatically substitute without the physician's knowledge (Fig. 4). One participant explained that: "Within our hospital, the decision concerning the usage of biosimilar or [originator] biologic drug is made by both physician and pharmacist." Men more often than women agreed to allow the pharmacists to substitute an originator biologic medicine with a biosimilar without consulting with a physician ( 9 of 19 men and 6 of 40 women answered positively). The difference was statistically significant $(p=0.00763)$. Moreover, pharmacists with longer work experience (more than 10 years) held more positive perceptions towards interchanging the drugs
Fig. 2 Advantages of biosimilars in comparison to biologic medicines $(n=60)$

\section{Advantages of biosimilars}

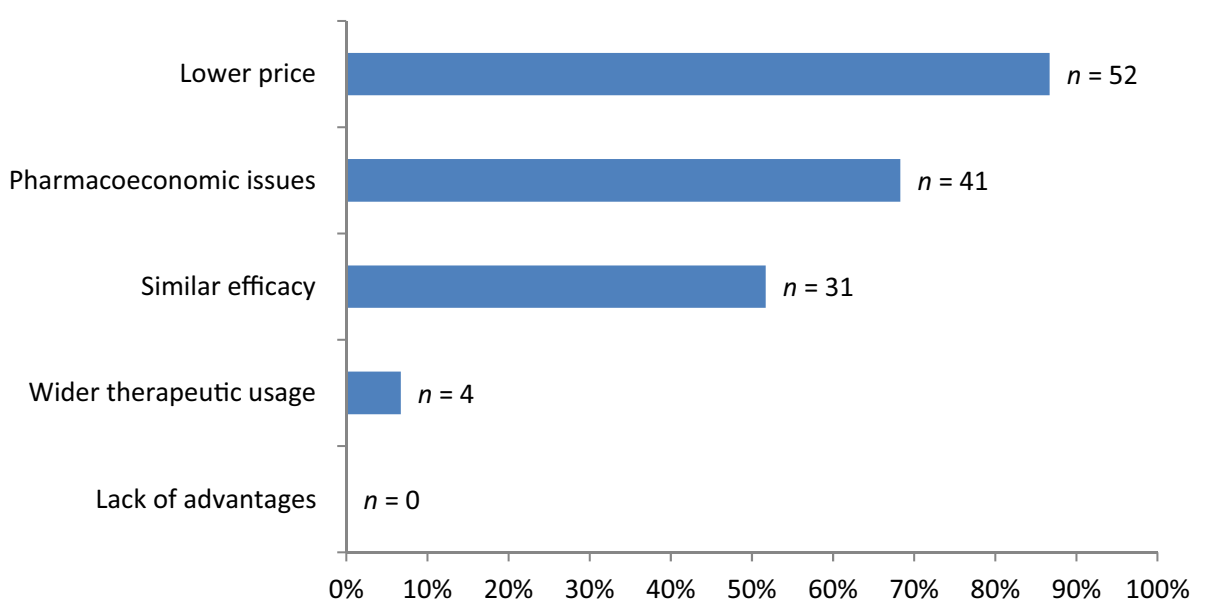


Fig. 3 Disadvantages of biosimilars in comparison to biologic medicines $(n=60)$
Fig. 4 Hospital pharmacist opinions on the interchanging of biologics and biosimilars $(n=60)$

\section{Disadvantages of biosimilars}

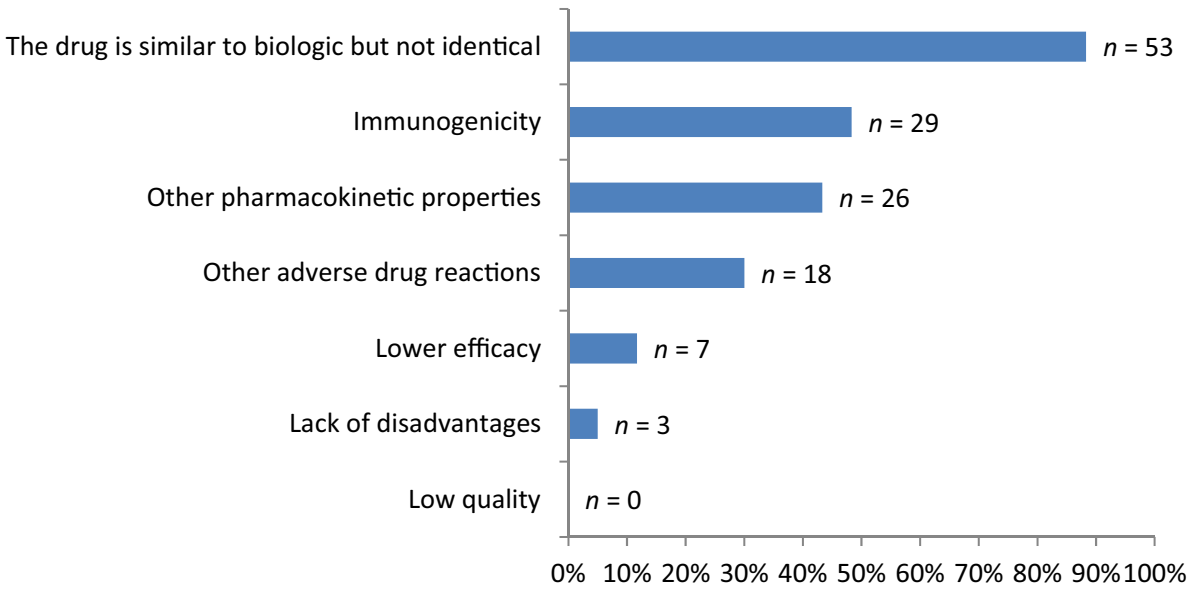

\section{Do you think that pharmacists can interchange a biologic to a biosimilar drug without the doctor's permission?}

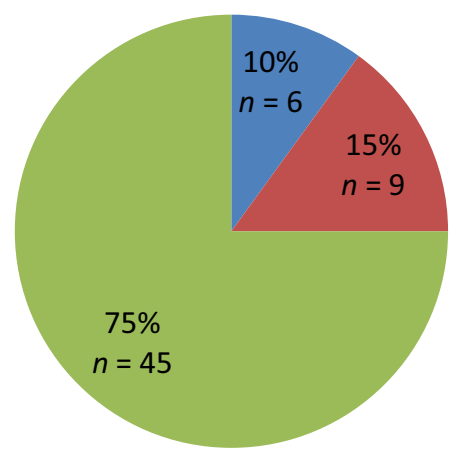

without doctors' permission than younger workers (statistical significance, $p=0.01545$ ). Qualitative responses from open-answer questions validate these findings and read as follows:

Participant No. 39: "If it is possible changes [biosimilar to biologic] should be discussed with a physician. ... If [the] physician does not agree to change the drug [they] must indicate: 'do not change' or 'dispense as written'."

Participant No. 44: "Biosimilar should be not used in therapy because they are only biosimilar!"

\section{Discussion}

This study is the first to explore hospital pharmacist attitudes to biosimilars and to investigate practice related to their usage in pharmacotherapy regimens in Poland. The literature presents studies from the USA, Belgium, France, Germany, Italy, Ireland, Malta, Hungary and UK as well as multiple European states [18]. The data obtained are especially valuable, since in recent years many originator biological medicines have lost their patent protection, allowing the introduction of biosimilars into therapy. This, in turn, has led to discussions between health institutions, physicians, pharmacists and other healthcare decision makers about their application and use for hospital inpatients. 
The survey highlighted that the majority of Polish hospitals offered originator biologic medicines and more than three-quarters of hospitals used biosimilars. Interestingly, taking into account the total volumes of medicines used within the hospitals, originator biologics are still much more often utilised than biosimilars. It can be assumed that due to the decreasing costs and policies of the national health insurance, the new medicines will be more commonly used in the near future [19]. Currently, medicine procurement in Polish hospitals is achieved through a tender process. Pharmacists are members of Tender Committees due to their comprehensive knowledge of the pharmaceutical market. According to the rules of tenders, among medicines that have the same International Nonproprietary Name (INN), those with the lowest prices are chosen for use. This is also applicable to biologic medicines. However, in some cases, the hospital may choose to order brand name medicines (the originator biologics) for specific patients (e.g. those who do not tolerate other medicines). Furthermore, many physicians prefer to continue therapy with the same medicine; therefore, in some circumstances even more expensive medicines may be ordered. In addition, sometimes the registration process of biosimilars and originator biologics differs from each other due to differences in details such as route of administration or indication, which may have an impact on winning the tender. It is also worth mentioning that biosimilars are not always cheaper than reference medicines. Sometimes, the manufacturers of originator biologics decrease the price of these medicines after the introduction of biosimilars onto the market, fostering the development of competition on the pharmaceutical market. Moreover, large hospitals may have the opportunity to negotiate drug prices during tenders. Currently, the system and policy of supplying biological medicines within Polish hospitals is still developing and will continue to evolve to allow for the achievement of cost efficiency as well as effective and safe treatment. Despite their short time in the pharmaceutical market, the majority of participants expressed familiarity with biosimilars. Moreover, the findings suggest that the respondents were conscious of and understood the problems associated with biosimilars. A similar or slightly higher level of knowledge about biosimilars was identified in studies from the UK, New Zealand, Ireland and the USA [7, 12, 20, 21]. Nevertheless, there are still observed gaps in biosimilar knowledge, which is contributing to limited prescribing [18]. Biosimilar medicines are new drugs and the introduction of education regarding them may stimulate their utilisation within hospitals. Healthcare professionals must continuously update their knowledge through lifelong learning sessions, attending special courses and conferences and reading literature to maintain currency of practice. Furthermore, students who are now studying healthcare courses require adequate training; therefore, the study curriculum should be adjusted according to modern trends. Leonard et al. [18] highlighted in their systematic review that key areas of health provider education for improving knowledge and acceptance of biosimilar medicines to promote their uptake related to immunogenicity, clinical trial evidence, extrapolation and interchangeability.

Most of the surveyed Polish pharmacists believed that biosimilars should be used at the initiation of therapy, and when the reference medicine is ineffective. The latter answer was given more often by pharmacists without specialisation and it may suggest that those pharmacists do not have a comprehensive level of knowledge about biosimilars in comparison to specialised pharmacists. Only $23 \%$ of pharmacists thought that the reference medicine could be substituted by a biosimilar during therapy. Inotai et al. [22] also suggested that beginning therapy with a biosimilar was a well-established practice, whereas switching an originator biologic to a biosimilar during therapy was a problem for clinicians. However, the authors concluded that the concerns regarding switching patients who are stabilised on a biologic treatment to a biosimilar are disproportional to the cost savings and improvement of patient access to these new medicines [22].

The next part of the survey related to the positive and negative aspects of the use of biosimilars. Regarding the advantages, answers associated with a decreased cost of therapy were indicated most often. The same response was identified by professionals in the UK when asked about substituting biosimilar infliximab and insulin glargine [20]. Furthermore, in the study by Hemmington et al. [21] $21.3 \%$ of specialised physicians indicated that they would explain to their patients that biosimilars are a cost-effective option. The usage of biosimilars may allow facilities to save costs; in some countries and under certain circumstances biosimilars can be much cheaper than reference medicines and more patients could receive this modern therapy [23-25]. Community and hospital pharmacists (92\%) from France indicated "Health care costs savings" as their motivation to promote the prescribing of biosimilars [26]. These arguments make biosimilar medicines very attractive, especially for Eastern European countries with limited healthcare budgets [27].

With respect to disadvantages of biosimilars, the issues most often indicated related to the perceived dissimilarities with originator biologics, immunogenicity, other pharmacokinetic properties and adverse drug reactions. Similarly, limited evidence on therapeutic equivalence and adverse immunologic reactions were identified as major concerns by experts from Eastern European countries relating to the use of biosimilars [27]. Weise et al. [28] presented the most frequent concerns from the perspective of clinicians regarding the use of biosimilars, which included pharmaceutical quality, interchangeability with the original product, clinical efficacy and safety in extrapolated indications without clinical studies [28]. In another study, patients also expressed their concerns about the 
safety of biosimilars and they believed that the physician should make the decision about the inclusion of biosimilars in therapy [29]. In contrast, 85\% of pharmacists from the Lombardy region of Italy believed that biosimilars had comparable efficacy and safety to reference products, and only $14.7 \%$ were afraid of a higher risk of immunogenicity and poor-quality trials [30].

Most pharmacists in our study felt that pharmacist-led substitution was not appropriate. However, there were also pharmacists who had no doubts regarding interchanging originator biologics and biosimilars without a physician's consultation. Polish law does not regulate the substitution of biologics to biosimilars. Moreover, in Poland there are no national guidelines related to this form of substitution [15]. The Polish Task Force was established comprising 13 experts, including professionals involved in various aspects of the usage of biosimilars. The Task Force reached consensus when considering the introduction of these new drugs into the pharmaceutical market. These professionals determined that biosimilars are an important component of biological pharmacotherapy regimens as they reduce costs and allow for more patients to be treated by this modern therapy. However, according to the experts, the safety of biosimilars must be monitored. There was also no consensus reached when considering automatic substitution [31]. In January 2019 a meeting was held during which the previous consensus was debated in light of new findings. The experts believed that updated knowledge and interdisciplinary agreement was necessary for the responsible, effective and safe treatment of patients with originator biological and biosimilar preparations in Poland. The costs of therapy would decrease due to the availability of biosimilars, thus more patients would have access to this kind of treatment. The registered biosimilars could be used as biologics under the same indications and contraindications, as monotherapy or as combined treatment. The current research confirms that a single interchange between originator biologics and biosimilars is safe and does not affect the effectiveness of the medicine (multiple interchanging is not recommended). Both the patient and the physician must be aware of the switch/substitution. Moreover, for some drugs, the experts allow automatic substitution without physician participation. In selected clinical situations and patient groups, evaluation and monitoring of the immunogenicity of the biosimilars can be provided [32].

Our results are in accordance with the global survey concerning pharmacy-mediated substitution of biosimilars. The authors of that study claimed that in Poland, similarly to other European Union countries (Belarus, Estania, Finland, France, Latvia, Serbia), there is restricted substitution. According to their study, Polish pharmacists may substitute the medicines "so long as the prescribing physician has not indicated otherwise using an opt-out provision" [33].
In a study conducted in Ireland, the majority of physicians surveyed (more than 95\%) believed that community pharmacists should not dispense a biosimilar in place of an original medicine without prescriber knowledge. In the same study, most of the pharmacists surveyed (58\%) preferred that original medicines be substituted in consultation with a prescriber, $14 \%$ preferred to make their own decision regarding suitable substitution and $27 \%$ would preferred to not substitute at all [12].

In another study exploring the perceptions of US dermatologists, $88 \%$ believed that pharmacists would like to substitute a biologic with a biosimilar without prescriber consultation [34]. A questionnaire completed by 1696 patients in the USA indicated that non-medical switching to biosimilars might negatively impact treatment outcomes, i.e. $85 \%$ of those surveyed didn't want to switch to a biosimilar if their current biologic was effective and $83 \%$ of patients were afraid of adverse drug reactions following switching [35].

\section{Limitations}

While this is the first study in Poland to examine pharmacist attitudes to biosimilars, some limitations to the survey must be discussed. The response rate was $22.5 \%$ and the results may not be representative of all hospital pharmacists in Poland. We assume that pharmacists who are not involved in the dispensing of biosimilars declined to participate in this study. The study was anonymous, and therefore we cannot identify the pharmacists who did not take part in the survey. There were also no incentives provided for the respondents, and these could have increased the response rate. The survey was undertaken at a particular timepoint, and the attitudes of pharmacists may evolve and change over time. It will be valuable to repeat a similar study in several years and then evaluate whether perceptions have changed.

The survey was very short and detailed information was not obtained, and the questionnaire was not validated. Nevertheless, the brief form of the questionnaire may have increased the willingness of participants to complete the survey. However, the study included 61 respondents, which makes the sample size modest and not big enough for a detailed statistical analysis. We also did not collect any data from physicians, nurses or patients regarding biosimilars. This could be an area of future research.

\section{Conclusion}

The usage of biologic medicines, including originator biologics and biosimilars, is still developing. Many of these medicines are being introduced within Polish hospitals and 
there are many challenges facing physicians, nurses and hospital pharmacists as well as patients and their families.

Overall, biosimilars are available within Polish hospitals and pharmacists are involved in their distribution. However, our findings highlight that the use of biosimilars in therapy is still a cause of controversy among hospital pharmacists when considering their nature, immunogenicity and safety. Thus, it must be underlined that the monitoring of adverse drug reactions may increase the safe usage of biologic therapy and decrease the concerns regarding their usage among healthcare providers. In clinical practice, interchangeability, especially during stable patient treatment, raised concerns among surveyed pharmacists. On the other hand, all respondents agreed that biosimilars are substantial cost-saving measures for hospitals. The authors believe that decreasing the costs of biologic therapy will stimulate their usage in more patients. These findings reflect the fact that there is a need for more precise legal regulations concerning the usage of biosimilars. Moreover, there is a need for improved communication between physicians and pharmacists as well as the introduction of evidence-based educational initiatives to improve the implementation of biosimilars in Polish practice. The more patients are prescribed modern biologic therapies, the more information about these new drugs will be obtained.

Acknowledgements The authors would like to thank all hospital pharmacists who participated in the study and shared their opinions related to the examined topic.

\section{Compliance with Ethical Standards}

Funding No funding was received for the conduct of this study.

Conflict of interest Iga Pawłowska, Leszek Pawłowski, Natalia Krzyżaniak and Ivan Kocić declare no conflicts of interest.

Ethical approval The study did not examine any human participants, but only contained the opinions of hospital pharmacists related to the subject of the study. The study was anonymous and voluntary and the participants could refuse to participate in the study.

Open Access This article is distributed under the terms of the Creative Commons Attribution-NonCommercial 4.0 International License (http://creativecommons.org/licenses/by-nc/4.0/), which permits any noncommercial use, distribution, and reproduction in any medium, provided you give appropriate credit to the original author(s) and the source, provide a link to the Creative Commons license, and indicate if changes were made.

\section{References}

1. Jarrett S, Dingermann T. Biosimilars are here: a hospital pharmacist's guide to educating health care professionals on biosimilars. Hosp Pharm. 2015;50:884-93.
2. Kurki P, van Aerts L, Wolff-Holz E, Giezen T, Skibeli V, Weise M. Interchangeability of biosimilars: a European perspective. BioDrugs. 2017;31:83-91.

3. Tsiftsoglou AS, Ruiz S, Schneider CK. Development and regulation of biosimilars: current status and future challenges. BioDrugs. 2013;27:203-11.

4. Bressler B, Dingermann T. Establishing a new marketplace for biologic therapy with biosimilar agents - importance of extrapolation of data. Biosimilars. 2015;5:41-8.

5. Stanhope R, Sörgel F, Gravel P, Pannatier Schuetz YB, Zabransky M, Muenzberg M. Bioequivalence studies of omnitrope, the first biosimilar/rhGH follow-on protein: two comparative phase 1 randomized studies and population pharmacokinetic analysis. J Clin Pharmacol. 2010;50(11):1339-48.

6. US Food and Drug Administration. Biosimilars: more treatment choices and innovation. https://www.fda.gov/ForConsume rs/ConsumerUpdates/ucm436399.htm. Accessed 27 Nov 2018.

7. Cohen H, Beydoun D, Chien D, Lessor T, McCabe D, Muenzberg $\mathrm{M}$, et al. Awareness, knowledge, and perceptions of biosimilars among specialty physicians. Adv Ther. 2017;33:2160-72.

8. Sieczkowska-Golub J, Jarzebicka D, Oracz G, Kierkus J. Biosimilars in paediatric inflammatory bowel disease. World J Gastroenterol. 2018;24:4021-7.

9. Centrally authorised biosimilar medicines - European Medicines Agency. https://www.ema.europa.eu/medicines/field _ema_web_categories\%253Aname_field/Human/ema_group _types/ema_medicine/field_ema_med_status/authorised-36/ ema_medicine_types/field_ema_med_biosimilar/search_api_ aggregation_ema_medicine_types/field_ema_med_biosimilar. Accessed 23 Oct 2018.

10. EMA approves adalimumab and pegfilgrastim biosimilars. http://www.gabionline.net/Biosimilars/News/EMA-approvesadalimumab-and-pegfilgrastim-biosimilars. Accessed 27 Nov 2018.

11. Biosimilar medicines: overview. https://www.ema.europa.eu/en/ human-regulatory/overview/biosimilar-medicines. Accessed 27 Nov 2018.

12. O'Callaghan J, Bermingham M, Leonard M, Hallinan F, Morris $\mathrm{JM}$, Moore U, et al. Assessing awareness and attitudes of healthcare professionals on the use of biosimilar medicines: a survey of physicians and pharmacists in Ireland. Regul Toxicol Pharmacol. 2017;88:252-61.

13. Calvo B, Martinez-Gorostiaga J, Echevarria E. The surge in biosimilars: considerations for effective pharmacovigilance and EU regulation. Ther Adv Drug Saf. 2018;9:601-8.

14. Portela MDCC, Sinogas C, Albuquerque de Almeida F, BaptistaLeite R, Castro-Caldas A. Biologicals and biosimilars: safety issues in Europe. Expert Opin Biol Ther. 2017;17:871-7.

15. Wysocki PJ, Krzakowski M, Walewski J, Duszyńska M, Wojtukiewicz MZ, Kowalski D, et al. Stanowisko Polskiego Towarzystwa Onkologii Klinicznej w sprawie wprowadzenia krajowych standardów stosowania leków biologicznych [in Polish]. Onkol Prakt Klin Edu. 2017;3:293-8.

16. Stevenson JG, Popovian R, Jacobs I, Hurst S, Shane LG. Biosimilars: practical considerations for pharmacists. Ann Pharmacother. 2017;51:590-602.

17. Pawłowska I, Pawłowski L, Kocić I, Krzyżaniak N. Clinical and conventional pharmacy services in Polish hospitals: a national survey. Int J Clin Pharm. 2016;38:271-9.

18. Leonard E, Wascovich M, Oskouei S, Gurz P, Carpenter D. Factors affecting health care provider knowledge and acceptance of biosimilar medicines: a systematic review. J Manag Care Spec Pharm. 2019;25:102-12.

19. Bachanek O, Mitura J, Pawlikowski J. Dostępność i ograniczenia w stosowaniu leczenia biologicznego w Polsce [in Polish]. Med Og Nauk Zdr. 2015;21:266-71. 
20. Chapman SR, Fitzpatrick RW, Aladul MI. Knowledge, attitude and practice of healthcare professionals towards infliximab and insulin glargine biosimilars: result of a UK web-based survey. BMJ Open. 2017;7:e16730.

21. Hemmington A, Dalbeth N, Jarrett P, Fraser AG, Broom R, Browett $\mathrm{P}$, et al. Medical specialists' attitudes to prescribing biosimilars. Pharmacoepidemiol Drug Saf. 2017;26:570-7.

22. Inotai A, Prins CPJ, Csanádi M, Vitezic D, Codreanu C, Kaló $\mathrm{Z}$. Is there a reason for concern or is it just hype? A systematic literature review of the clinical consequences of switching from originator biologics to biosimilars. Expert Opin Biol Ther. 2017;17:915-26.

23. McCall C. Biosimilars for insulin: a cost-saving alternative? Lancet. 2018;11(392):463-4.

24. Blackstone EA, Joseph PF. The economics of biosimilars. Am Health Drug Benefits. 2013;6:469-78.

25. Beck M, Michel B, Rybarczyk-Vigouret M-C, Sordet C, Sibilia J, Velten M. Biosimilar infliximab for the management of rheumatoid arthritis in France: what are the expected savings? Eur J Hosp Pharm Sci Pract. 2017;24:85-90.

26. Beck M, Michel B, Rybarczyk-Vigouret MC, Levêque D, Sordet $\mathrm{C}$, Sibilia J, et al. Knowledge, behaviors and practices of community and hospital pharmacists towards biosimilar medicines: results of a French web-based survey. MAbs. 2017;9:383-90.

27. Inotai A, Csanadi M, Petrova G, Dimitrova M, Bochenek T, Tesar $\mathrm{T}$, et al. Patient access, unmet medical need, expected benefits, and concerns related to the utilisation of biosimilars in Eastern European countries: a survey of experts. Biomed Res Int. 2018;2018:9597362.

28. Weise M, Bielsky MC, De Smet K, Ehmann F, Ekman N, Giezen TJ, et al. Biosimilars: what clinicians should know. Blood. 2012;120:5111-7.
29. van Overbeeke E, De Beleyr B, de Hoon J, Westhovens R, Huys I. Perception of originator biologics and biosimilars: a survey among Belgian rheumatoid arthritis patients and rheumatologists. BioDrugs. 2017;31:447-59.

30. Pasina L, Casadei G, Nobili A. A survey among hospital specialists and pharmacists about biosimilars. Eur J Intern Med. 2016;35:e31-3.

31. Jahnz-Rozyk K, Wiesik-Szewczyk E, Ekspertów G. The Polish Task Force position statement on safety of biologic treatment with monoclonal antibodies and soluble receptors [in Polish]. Pol Merkur Lekarski. 2014;37:5-9.

32. Information of the Polish Task Force related to the usage of biosimilars in Poland [in Polish]. http://www.kierunekfarmacja.pl/ artykul,60720,polska-grupa-ekspertow-ds-bezpieczenstwa-stoso wania-terapii-biologicznych-mamy-konsensus-w-sprawie-terap ii-biologicznych-referencyjnych-i-biopodobnych.html. Accessed 20 Jan 2019.

33. Larkin H, Macdonald J, Lumsden R. Pharmacy-mediated substitution of biosimilars - a global survey benchmarking country substitution policies. GaBI J. 2017;6:157-64.

34. Barsell A, Rengifo-Pardo M, Ehrlich A. A survey assessment of US dermatologists' perception of biosimilars. J Drugs Dermatol. 2017;16:612-5.

35. Teeple A, Ginsburg S, Howard L, Huff L, Reynolds C, Walls D, et al. Patient attitudes about non-medical switching to biosimilars: results from an online patient survey in the United States. Curr Med Res Opin (Epub 2019 Jan 8). https://doi.org/10.1080/03007 995.2018.1560221. 